\title{
Buprenorphine Telehealth Treatment Initiation and Follow-Up During COVID-19
}

J Gen Intern Med 37(5):1331-3

DOI: $10.1007 / \mathrm{s} 11606-021-07249-8$

(C) Society of General Internal Medicine 2021

\section{INTRODUCTION}

Opioid overdose deaths surged during the COVID-19 pandemic, increasing 30\% in 2020 compared to $2019 .{ }^{1}$ Medications for opioid use disorder (MOUD) are one component of an evidence-based strategy to reduce opioid-related morbidity and mortality. Opioid use disorder (OUD) treatment with buprenorphine and methadone reduces mortality by half $f^{2}$; however, less than $35 \%$ of the two million people living with OUD in the USA receive MOUD. ${ }^{3,4}$

Recognizing the dire consequences of worsening buprenorphine access during the pandemic, in March 2020, the Department of Health and Human Services, the Attorney General, and the Drug Enforcement Administration exercised regulatory and enforcement discretion to permit the delivery of audioonly telehealth and for waivered clinicians to initiate buprenorphine treatment by audio or audiovisual telehealth without requiring an in-person evaluation.

In this new regulatory environment, authorized clinicians began providing buprenorphine treatment by telehealth (telebuprenorphine). ${ }^{5}$ Audiovisual telehealth has been shown to be effective for buprenorphine maintenance treatment prior to COVID-19, but use of telehealth for buprenorphine treatment initiation, and the use of audio-only telehealth for either treatment initiation or maintenance, are not yet well described. Here, we describe characteristics of patients receiving telebuprenorphine at academic-affiliated buprenorphine clinics early in the COVID-19 pandemic in four states.

\section{METHODS}

We conducted a retrospective cohort study of patients receiving tele-buprenorphine from March to June 2020 at four clinics affiliated with academic medical centers in New York City, Philadelphia, San Francisco, and Rhode Island. Clinic and patient characteristics were collected using a standardized

Received July 13, 2021

Accepted October 25, 2021

Published online January 3, 2022 data collection instrument. Information included clinic type, funding source, type of telehealth provided (Table 1), patient demographics, and 30-day treatment retention.

Patients receiving tele-buprenorphine for treatment initiation or maintenance from March 2020 to June 2020 were included in the analysis. Treatment retention was identified through a query of each clinic's electronic health record and/or their state's prescription drug monitoring program and defined as presence of a follow-up clinic visit or subsequent buprenorphine prescription within 30 days of their index telehealth encounter. Data were deidentified and analyzed in aggregate at each study site. Aggregate data from each site was entered into a standardized REDCap database for analysis. Data analyzed are available from the corresponding author on reasonable request. The study was conducted in accordance with STROBE guidelines for observational studies and approved by the Lifespan, New York University, University of California San Francisco, University of Pennsylvania, and Rhode Island Department of Health Institutional Review Boards.

\section{RESULTS}

Across all sites, 159 people received tele-buprenorphine treatment from March to June 2020 (Table 2). Most were male $(76 \%, 121 / 159)$, nearly one quarter were Black non-Hispanic $(23.0 \%, 38 / 159)$, one third were White non-Hispanic (32.0\%, 49/159), 16\% were Hispanic/Latinx (24/159), and most were Medicaid enrollees $(74 \%, 117 / 159)$. The mean age was 43 years (range $20-73$ years). Most patients had prior experience with buprenorphine, either prescribed $(55 \%, 89 / 159)$ or non-prescribed $(21 \%, 34 / 159)$. Eighty-five percent (135/159) were treatment initiation visits. Over half were audio-only $(60 \%, 87 / 159)$. The proportion of patients with a return treatment visit within 30 days was $83 \%$ (132/159, range 80.0$91.3 \%)$.

\section{DISCUSSION}

Use of audiovisual and audio-only telehealth allowed for rapid scaleup of services at existing clinics within a matter of days to weeks and establishment of new programs in a range of academically affiliated clinics serving diverse patient populations during an evolving pandemic. Tele-buprenorphine for 
Table 1 Buprenorphine Telehealth Program Characteristics

\begin{tabular}{|c|c|c|c|c|}
\hline & $\begin{array}{l}\text { Site } 1 \\
\text { NYC Health + Hospitals } \\
\text { Virtual Buprenorphine } \\
\text { Clinic }\end{array}$ & $\begin{array}{l}\text { Site } 2 \\
\text { Rhode Island Buprenorphine } \\
\text { Hotline }\end{array}$ & $\begin{array}{l}\text { Site } 3 \\
\text { Zuckerberg San Francisco } \\
\text { General Bridge Clinic }\end{array}$ & $\begin{array}{l}\text { Site } 4 \\
\text { University of Pennsylvania } \\
\text { Outpatient Substance Use } \\
\text { Treatment Program }\end{array}$ \\
\hline $\begin{array}{l}\text { Organization } \\
\text { type }\end{array}$ & $\begin{array}{l}\text { Academic private non- } \\
\text { profit, city government }\end{array}$ & Academic private non-profit & Academic, county government & Academic private non-profit \\
\hline Funding source & $\begin{array}{l}\text { Government, insurance } \\
\text { reimbursement }\end{array}$ & $\begin{array}{l}\text { Government contract/grant } \\
\text { funded (CDC; SAMHSA) }\end{array}$ & Grant funded & Insurance reimbursement \\
\hline Clinic type & Bridge clinic* & Bridge clinic* & Bridge clinic* & Outpatient clinic \\
\hline $\begin{array}{l}\text { New or existing } \\
\text { program }\end{array}$ & New & New & $\begin{array}{l}\text { Existing, previously did not } \\
\text { offer telehealth }\end{array}$ & $\begin{array}{l}\text { Existing, previously did not } \\
\text { offer telehealth }\end{array}$ \\
\hline $\begin{array}{l}\text { Telehealth } \\
\text { capability }\end{array}$ & Audio and audiovisual & Audio only & Audio only & Audio and audiovisual \\
\hline $\begin{array}{l}\text { Date telehealth } \\
\text { visits launched }\end{array}$ & March 27, 2020 & April 15, 2020 & April 10, 2020 & March 23, 2020 \\
\hline In-person visits & Not offered & Not offered & Offered & Not offered \\
\hline $\begin{array}{l}\text { Clinic provider } \\
\text { specialties }\end{array}$ & $\begin{array}{l}\text { Addiction medicine, } \\
\text { addiction psychiatry }\end{array}$ & $\begin{array}{l}\text { Addiction medicine, } \\
\text { emergency medicine, internal } \\
\text { medicine, medical toxicology }\end{array}$ & $\begin{array}{l}\text { Addiction medicine, family } \\
\text { medicine, obstetrics, internal } \\
\text { medicine }\end{array}$ & $\begin{array}{l}\text { Emergency medicine, } \\
\text { psychiatry }\end{array}$ \\
\hline $\begin{array}{l}\text { Target } \\
\text { population }\end{array}$ & $\begin{array}{l}\text { People experiencing } \\
\text { homelessness; people } \\
\text { recently incarcerated }\end{array}$ & $\begin{array}{l}\text { People experiencing } \\
\text { homelessness; people recently } \\
\text { incarcerated; people } \\
\text { discharged from the } \\
\text { emergency department }\end{array}$ & $\begin{array}{l}\text { People experiencing } \\
\text { homelessness; people in } \\
\text { COVID-19 isolation/quarantine; } \\
\text { people discharged from the } \\
\text { emergency department or hospi- } \\
\text { tal }\end{array}$ & $\begin{array}{l}\text { People recently incarcerated; } \\
\text { people discharged from the } \\
\text { emergency department; people } \\
\text { calling institutional hotline for } \\
\text { support }\end{array}$ \\
\hline
\end{tabular}

*Bridge clinics provide treatment initiation and linkage to a provider who can provide maintenance treatment. Bridge clinics may follow patients over several visits until follow-up care is established. The duration of time site clinics continue treatment before maintenance referral varies by clinic and patient

treatment initiation is not only feasible, but most patients continued care in the 30 days following their initial telehealth visit. This is particularly notable because clinic outreach and the patient population served focused on individuals experiencing homelessness, people leaving incarceration, and Medicaid enrollees, many of whom encounter significant financial and logistical barriers to accessing treatment.

There are several limitations to this study. First, all study sites are connected to academic medical centers in urban areas, so findings may not be generalizable to other settings. While

Table 2 Characteristics of Patients Receiving Buprenorphine Telehealth, March-June 2020

\begin{tabular}{|c|c|c|c|c|c|}
\hline & $\begin{array}{l}\text { Total } \\
n(\%)\end{array}$ & $\begin{array}{l}\text { Site } 1 \\
n(\%)\end{array}$ & $\begin{array}{l}\text { Site } 2 \\
n(\%)\end{array}$ & $\begin{array}{l}\text { Site } 3 \\
n(\%)\end{array}$ & $\begin{array}{l}\text { Site } 4 \\
n(\%)\end{array}$ \\
\hline Number of patients & 159 & 109 & 15 & 12 & 23 \\
\hline Age, mean (range) & $43.0(20-73)$ & $45(21-73)$ & $39.8(20-59)$ & $48.7(26-60)$ & $38.4(25-66)$ \\
\hline \multicolumn{6}{|l|}{ Sex } \\
\hline Male & $121(76.0)$ & $91(83.5)$ & $10(66.7)$ & $10(83.3)$ & $10(43.5)$ \\
\hline Female & $38(24.0)$ & $18(16.5)$ & $5(33.3)$ & $2(16.7)$ & $13(56.5)$ \\
\hline \multicolumn{6}{|l|}{ Race-ethnicity } \\
\hline Black non-Hispanic & $35(23.0)$ & $19(18.5)$ & $2(13.3)$ & $8(66.7)$ & $6(26.1)$ \\
\hline White non-Hispanic & $49(32.0)$ & $27(26.2)$ & $10(66.7)$ & $2(16.7)$ & $10(43.5)$ \\
\hline Latinx/Hispanic & $24(16.0)$ & $21(20.4)$ & $0(0)$ & $0(0)$ & $3(13.0)$ \\
\hline Other & $45(29.0)$ & $36(35.0)$ & $3(20.0)$ & $2(16.7)$ & $4(17.4)$ \\
\hline \multicolumn{6}{|l|}{ Patient insurance } \\
\hline Uninsured & $8(5.0)$ & $8(7.3)$ & $0(0)$ & $0(0)$ & $0(0.0)$ \\
\hline Medicaid & $117(74.0)$ & $77(70.6)$ & $9(60)$ & $12(100)$ & $19(82.6)$ \\
\hline Medicare & $25(16.0)$ & $21(19.3)$ & $3(20)$ & $0(0)$ & $1(4.3)$ \\
\hline Other & $9(6.0)$ & $3(2.8)$ & $3(20)$ & $0(0)$ & $3(13.0)$ \\
\hline \multicolumn{6}{|l|}{ Prior buprenorphine experience } \\
\hline No & $40(25.0)$ & $20(18.9)$ & $2(13.3)$ & $9(0.8)$ & $6(26.1)$ \\
\hline Yes, prescribed & $89(55.0)$ & $20(18.9)$ & $6(40.0)$ & $2(16.7)$ & $12(52.2)$ \\
\hline Yes, not prescribed & $34(21.0)$ & $14(13.2)$ & $11(73.3)$ & $1(0.08)$ & $5(21.7)$ \\
\hline \multicolumn{6}{|l|}{ Initiation or maintenance visit } \\
\hline Initiation & $135(85.0)$ & $109(100)$ & $15(100)$ & $10(83.33)$ & $1(4.3 \%)$ \\
\hline Maintenance & $24(15.0)$ & $0(0)$ & $0(0)$ & $2(16.67)$ & $22(95.7 \%)$ \\
\hline \multicolumn{6}{|l|}{ Telehealth modality } \\
\hline Audio only & $87(60.0)$ & $52(52.5)$ & $15(100)$ & $12(100)$ & $8(38.1 \%)$ \\
\hline Audiovisual & $59(40.0)$ & $47(47.5)^{*}$ & $0(0)$ & $0(0)$ & $13(61.9 \%)$ \\
\hline \multicolumn{6}{|l|}{ Returned visit within 30 days of initiation } \\
\hline No & $27(17.0)$ & $20(18.4)$ & $3(20)$ & $2(16.7)$ & $2(8.7)$ \\
\hline Yes & $132(83.0)$ & $89(81.7)$ & $12(80.0)$ & $10(83.3)$ & $21(91.3)$ \\
\hline
\end{tabular}

*Patient had video-capable phone; record did not indicate whether audiovisual or just-audio call was performed. Note: \% represents percent of total number of patients for which information was available. \% may not add up to 100 due to rounding of decimal points 
two of the clinics (site 2 and site 3 ) did provide telebuprenorphine care for people living in rural areas, models of care described here may need to be adapted for implementation in suburban and rural areas. Second, visits across sites varied considerably during the 3-month study period. This is due to a combination of factors including but not limited to whether audio-only services were connected to a pre-existing or new clinic, referral sources, and clinic advertising and outreach.

Improving access to evidence-based addiction treatment is crucial to reduce overdose deaths but is just one part of a comprehensive approach to ending the current overdose crisis. Addressing social determinants of health and structural inequities, expanding harm reduction policies and programs, expanding access to mental health treatment, and drug decriminalization are evidence-based, public health approaches to reducing substance use-related morbidity and mortality. Tele-buprenorphine - even when delivered primarily via audio - presents an important opportunity to expand treatment access. Research about telehealth conducted during COVID19 has shown that individuals who are Black, Latinx/Hispanic, older, lower income, and female are less likely to use videobased telehealth services. Efforts aimed at improving OUD treatment access by telehealth which require a video interface may inadvertently perpetuate existing inequities in treatment access by geography, race, and income. Longer-term outcomes research is needed to evaluate audio-only versus video-based telehealth and in-person visits, but these data show that it is a promising low-barrier strategy to improve treatment access.

Elizabeth A. Samuels, MD, MPH, MHS ${ }^{1}$

Utsha G. Khatri, MD, MSHP ${ }^{2}$

Hannah Snyder, $M D^{3}$

Rachel S. Wightman, $M D^{1}$

Babak Tofighi, MD, MSc ${ }^{4}$

Noa Krawczyk, $P h D^{5}$

${ }^{1}$ Department of Emergency Medicine, Alpert Medical School of Brown University,

Providence, RI, USA

${ }^{2}$ Department of Emergency Medicine, Perelman School of Medicine, National Clinician Scholars Program, University of Pennsylvania,

Philadelphia, PA, USA

${ }^{3}$ Department of Family and Community Medicine, University of California,

San Francisco, San Francisco, CA, USA

${ }^{4}$ Department of Population Health, New York University Grossman School of Medicine,

New York City, NY, USA

${ }^{5}$ Center for Opioid Epidemiology and Policy, Department of Population Health, New York University Grossman School of Medicine,

New York City, NY, USA
Corresponding Author: Elizabeth A. Samuels, MD, MPH, MHS; Department of Emergency Medicine, Alpert Medical School of Brown University, Providence, RI, USA (e-mail: elizabeth_samuels@brown.edu).

Contributors The authors would like to thank Corey Davis, JD; Brendan Jacka, PhD; and Neha Reddy, MPH, for their contributions and feedback on this manuscript.

Funding Dr. Samuels is supported by an Advance Clinical and Translational Research Mentored Research Award at Brown University which is supported by a National Institute of General Medical Sciences IDeA-CTR grant (U54GM115677). Drs. Samuels and Wightman received additional support by a Centers for Disease Control and Prevention Overdose Data to Action Grant, the National Institute of General Medical Sciences COBRE on Opioids and Overdose (P20GM125507), and a Substance Abuse and Mental Health Services Administration Emergency Grant to Address Mental and Substance Use Disorders During COVID-19. Dr. Tofighi is supported by the National Institute on Drug Abuse (K23DA042140). The content is solely the responsibility of the authors and does not necessarily represent the official views of the Centers for Disease Control and Prevention, the National Institutes of Health, or the Substance Abuse Mental Health Services Administration.

\section{Declarations:}

Conflict of Interest: The authors have no conflicts of interest to disclose.

\section{REFERENCES}

1. Ahmad FB, Rossen LM, Sutton P. Provisional drug overdose death counts. National Center for Health Statistics. https://www.cdc.gov/ nchs/nvss/vsrr/drug-overdose-data.htm. Accessed 7 Aug 2021

2. Santo T Jr, Clark B, Hickman M, et al. Association of Opioid Agonist Treatment With All-Cause Mortality and Specific Causes of Death Among People With Opioid Dependence: A Systematic Review and Meta-analysis. JAMA Psychiatry. 2021. https://doi.org/10.1001/jamapsychiatry.2021. 0976

3. Substance Abuse and Mental Health Services Administration. Key substance use and mental health indicators in the United States: Results from the 2018 National Survey on Drug Use and Health. Vol. HHS Publication No. PEP19-5068, NSDUH Series H-54. 2019. https://www.samhsa.gov/ data/.

4. Jones CM, McCance-Katz EF. Co-occurring substance use and mental disorders among adults with opioid use disorder. Drug Alcohol Depend. 2019;197:78-82. https://doi.org/10.1016/j.drugalcdep.2018.12.030

5. Uscher-Pines L, Huskamp HA, Mehrotra A. Treating Patients With Opioid Use Disorder in Their Homes: An Emerging Treatment Model. Jama. 2020;324(1):39-40. https://doi.org/10.1001/jama.2020.3940.

Publisher's Note: Springer Nature remains neutral with regard to jurisdictional claims in published maps and institutional affiliations. 